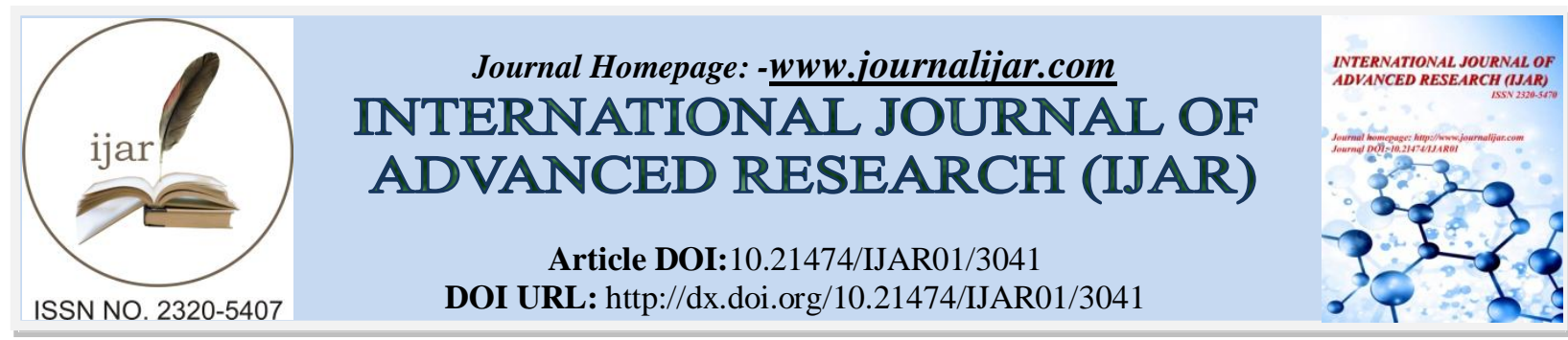

RESEARCH ARTICLE

\title{
PREVALENCE OF CARIES IN ANTERIOR TEETH IN DAKSHINA KANNADA POPULATION
}

Prof. Dr. Mithra N. Hegde ${ }^{1}$, Dr. Vandana Sadananda ${ }^{2}$ and Dr. Sinita Roberts ${ }^{3}$.

1. Vice Principal, Dean of Dental Faculty, Head - Department of Conservative Dentistry and Endodontics, A. B. Shetty Memorial Institute of Dental Sciences, Nitte University.

2. Post Graduate student, Department of Conservative Dentistry and Endodontics, A. B. Shetty Memorial Institute of Dental Sciences, Nitte University.

3. Department of Conservative Dentistry and Endodontics, A. B. Shetty Memorial Institute of Dental Sciences, Nitte University.

\section{Manuscript Info}

Manuscript History

Received: 30 November 2016

Final Accepted: 28 December 2016

Published: January 2017

Key words:-

Age, diet, tooth surface, location

\section{Abstract}

The aim of the survey was to determine the prevalence of caries in the anterior teeth in the Dakshina Kannada population. The basic research design included performance of dental examination based on WHO criteria and questionnaire survey on 4000 patients from the Dakshina Kannada district visiting the outpatient section of the Department of Conservative Dentistry and Endodontics and Rural Satellite Centres of A. B. Shetty Memorial Institute of Dental Sciences, Nitte University, Deralakatte, Mangalurufrom 2014 to 2015. The data obtained were statistically analyzed. A significant correlation was deduced between gender, age, diet, oral hygiene habits and caries of the anterior teeth

Copy Right, IJAR, 2016, All rights reserved.

\section{Introduction:-}

Dental caries as old as humankind is a chronic, infectious disease caused by bacterial by-products that leads to the dissolution of the tooth surface. ${ }^{1}$ Dynamic balance between demineralizing and remineralizing factors determines the eventual outcome of dental caries. Demineralizing factors include acidogenic bacteria, inhibited salivary function and frequency of ingestion of fermentable carbohydrates. Dental caries manifests as a continuum of disease states ranging from subclinical atomic level of demineralization to frank cavitation. ${ }^{2}$ Caries is largely preventable by early diagnosis, identification of individual risk factors, patient counselling and education, and initiation of preventive care procedures. The progressive nature of dental disease can quickly diminish the general health and quality of life especially in the case of caries in anterior teeth. Failure to identify and prevent dental disease leads to consequential and long-term adverse effects. Untreated dental disease can compromise the patient's ability to eat, sleep and function well at home and the society. An aesthetic healthy smile in addition to being an important determinant of overall physical aesthetics has been observed to have a considerable bearing on social interaction, playing an important role in how an individual is felt and perceived by others. The unaesthetic nature of untreated anterior carious teeth can also compromise the individual's self-esteem and social development leading to intense psychological repercussions in certain instances. Despite significant achievements in public health programmes individuals still suffer from dental caries and are without basic dental care. ${ }^{3}$ The infectious dental disease is reversible, if detected early enough. Establishment of a healthy lifestyle, good oral hygiene and nutrition, periodic oral health check-up is of paramount importance to prevent dental caries. 
An insight pertaining to the aetiology of dental caries may be provided form a patient's caries pattern. Hence adequate knowledge and information regarding the prevalence of caries will form the inherent basis for caries prevention programmes and treatment plans. This survey conducted aimed at determining the prevalence of caries in the anterior teeth based on gender, age, location, diet, frequency of oral hygiene measure practiced and surface of the tooth involved.

\section{Materials and Methodology:-}

An epidemiological study was conducted on 4000 patients in the year 2014 and 2015 aged above 15 years randomly selected from the outpatient department of A. B. Shetty Memorial Institute of Dental Sciences and satellite rural centres of Nitte University. Subsequent to obtaining permission from the ethical clearance committee of the institute and written consent from the patients a standardized prepared questionnaire based on the WHO Oral Health Assessment form 2013 was filled by the clinical examiner prior to and after the clinical examination.

Inclusion Criteria:-

Male and female patients aged above 15 years of age

Anterior maxillary and mandibular teeth

Exclusion Criteria:-

Patients with intellectual disability

Patients undergoing orthodontic treatment

Edentulous patients

Maxillary and mandibular premolars and molars

Armamentarium used for the examination was sterile mouth mirror, probe, tweezer and cotton rolls.

The patients were examined for anterior caries on a dental chair under adequate illumination. The data collected were analyzed statistically.

\section{Results:-}

Table 1:- Total prevalence of caries in anterior teeth

\begin{tabular}{|l|l|l|l|}
\hline \multicolumn{2}{|l|}{ TOTAL PATIENTS } & \multicolumn{3}{l|}{ PATIENTS WITH ANTERIOR CARIES } \\
\hline $\mathbf{2 0 1 4}$ & $\mathbf{2 0 1 5}$ & $\mathbf{2 0 1 4}$ & $\mathbf{2 0 1 5}$ \\
\hline 2000 & 2000 & $480(24 \%)$ & $402(20.1 \%)$ \\
\hline
\end{tabular}

Out of the 4000 patients examined over a period of 2 years, caries in the anterior teeth was observed in 480 (24\%) and $402(20.1 \%)$ patients in the year 2014 and 2015 respectively.

Table 2:- Prevalence of caries in different age groups

\begin{tabular}{|l|l|l|l|l|}
\hline \multirow{2}{*}{$\begin{array}{l}\text { AGE GROUP (IN } \\
\text { YEARS) }\end{array}$} & \multicolumn{2}{|l|}{ TOTAL PATIENTS } & \multicolumn{2}{l|}{ PATIENTS WITH ANTERIOR CARIES } \\
\cline { 2 - 5 } & $\mathbf{2 0 1 4}$ & $\mathbf{2 0 1 5}$ & $\mathbf{2 0 1 4}$ & $\mathbf{2 0 1 5}$ \\
\hline $15-25$ & 200 & 264 & $10(02.08 \%)$ & $9(02.23 \%)$ \\
\hline $26-35$ & 280 & 424 & $30(06.25 \%)$ & $42(10.45 \%)$ \\
\hline $\mathbf{3 6 - 4 5}$ & $\mathbf{4 4 0}$ & $\mathbf{5 0 9}$ & $\mathbf{1 7 0}(\mathbf{3 5 . 4 2 \%})$ & $\mathbf{1 8 8}(\mathbf{4 6 . 7 7 \%})$ \\
\hline $46-55$ & 480 & $155(32.29 \%)$ & $96(23.88 \%)$ \\
\hline $56-65$ & 400 & 308 & $65(13.54 \%)$ & $43(10.70 \%)$ \\
\hline$>65$ & 200 & 178 & $50(10.42 \%)$ & $24(05.97 \%)$ \\
\hline
\end{tabular}

Highest prevalence of caries was observed in the age group of 36 - 45 years 170 (35.2\%) in the year 2014 and 188 $(46.7 \%)$ in 2015 followed by $46-55$ years.

Table 3:- Prevalence of caries based on gender

\begin{tabular}{|l|l|l|l|l|}
\hline \multirow{2}{*}{ GENDER } & \multicolumn{2}{|l|}{ TOTAL PATIENTS } & \multicolumn{2}{l|}{ PATIENTS WITH ANTERIOR CARIES } \\
\cline { 2 - 5 } & $\mathbf{2 0 1 4}$ & $\mathbf{2 0 1 5}$ & $\mathbf{2 0 1 4}$ & $\mathbf{2 0 1 5}$ \\
\hline FEMALE & 1200 & 919 & $200(41.60 \%)$ & $175(43.53 \%)$ \\
\hline MALE & $\mathbf{8 0 0}$ & $\mathbf{1 0 8 1}$ & $\mathbf{2 8 0}(\mathbf{5 8 . 3 0 \%})$ & $\mathbf{2 2 7}(\mathbf{5 6 . 4 6 \%})$ \\
\hline
\end{tabular}

Males exhibited higher prevalence of caries in anterior teeth $280(58.30 \%)$ and $227(56.46 \%)$ when compared to the female gender 
Table 4:- Prevalence of caries based on location

\begin{tabular}{|l|l|l|l|l|}
\hline \multirow{2}{*}{ LOCATION } & \multicolumn{2}{l|}{ TOTAL PATIENTS } & \multicolumn{2}{l|}{ PATIENTS WITH ANTERIOR CARIES } \\
\cline { 2 - 5 } & $\mathbf{2 0 1 4}$ & $\mathbf{2 0 1 5}$ & $\mathbf{2 0 1 4}$ & $\mathbf{2 0 1 5}$ \\
\hline RURAL & 1247 & 1341 & $260(54.17 \%)$ & $180(44.77 \%)$ \\
\hline URBAN & 753 & 659 & $220(45.83 \%)$ & $180(44.77 \%)$ \\
\hline
\end{tabular}

The prevalence of caries in anterior teeth in the year 2014 was higher in the rural population 260 (54.17\%) when compared to the urban population, whereas in the year 2015 the prevalence of caries was $44.7 \%$ in both the rural and urban population.

Table 5:- Prevalence of caries based on diet

\begin{tabular}{|l|l|l|l|l|}
\hline \multirow{2}{*}{ DIET } & \multicolumn{2}{|l|}{ TOTAL PATIENTS } & \multicolumn{2}{l|}{ PATIENTS WITH ANTERIOR CARIES } \\
\cline { 2 - 5 } & $\mathbf{2 0 1 4}$ & $\mathbf{2 0 1 5}$ & $\mathbf{2 0 1 4}$ & $\mathbf{2 0 1 5}$ \\
\hline VEGETARIANS & 480 & 370 & $150(31.25 \%)$ & $127(31.59 \%)$ \\
\hline $\begin{array}{l}\text { MIXED DIET INCLUDING } \\
\text { FISH }\end{array}$ & 1220 & 1430 & $130(27.08 \%)$ & $75(18.66 \%)$ \\
\hline $\begin{array}{l}\text { MIXED DIET EXCLUDING } \\
\text { FISH }\end{array}$ & $\mathbf{3 0 0}$ & $\mathbf{2 0 0}$ & $\mathbf{2 0 0 ( 4 1 . 6 6 \% )}$ & $\mathbf{2 0 0 ( 4 9 . 7 5 \% )}$ \\
\hline
\end{tabular}

The prevalence of caries in anterior teeth was observed to be more in patients following mixed diet but devoid of fish $41.66 \%$ in 2014 and $49.75 \%$ in 2015.

Table 6:- Prevalence of caries based on brushing frequency

\begin{tabular}{|l|l|l|l|l|}
\hline \multirow{2}{*}{ BRUSHING } & \multicolumn{2}{|l|}{ TOTAL PATIENTS } & \multicolumn{2}{l|}{ PATIENTS WITH ANTERIOR CARIES } \\
\cline { 2 - 5 } & $\mathbf{2 0 1 4}$ & $\mathbf{2 0 1 5}$ & $\mathbf{2 0 1 4}$ & $\mathbf{2 0 1 5}$ \\
\hline $\mathbf{1}$ & $\mathbf{1 3 1 4}$ & $\mathbf{1 3 4 3}$ & $\mathbf{2 4 9}(\mathbf{5 1 . 8 8 \%})$ & $\mathbf{1 9 8}(\mathbf{4 9 . 2 5 \%})$ \\
\hline 2 & 712 & 622 & $107(22.29 \%)$ & $99(24.63 \%)$ \\
\hline$>2$ & 74 & 35 & $124(25.83 \%)$ & $103(25.63 \%)$ \\
\hline
\end{tabular}

Prevalence of caries in anterior teeth was highest among patients brushing once daily $51.88 \%$ in 2014 and $49.25 \%$ in 2015.

Table 7:- Prevalence of caries based on specific anterior tooth

\begin{tabular}{|c|c|c|}
\hline \multirow{2}{*}{ TOOTH NUMBER } & NUMBER OF TEETH WITH CARIES & $\mathbf{2 0 1 5}$ \\
\cline { 2 - 3 } & $\mathbf{2 0 1 4}$ & $\mathbf{3 0 2}(\mathbf{3 3 . 8 2 \%})$ \\
\hline 11 & $\mathbf{3 2 5}(\mathbf{3 3 . 4 4 \% )}$ & $170(19.04 \%)$ \\
\hline 13 & $195(20.07 \%)$ & $17(01.90 \%)$ \\
\hline 21 & $15(01.54 \%)$ & $280(31.36 \%)$ \\
\hline 22 & $300(30.86 \%)$ & $7(01.90 \%))$ \\
\hline 23 & $27(02.77 \%)$ & $17(01.90 \%)$ \\
\hline 31 & $6(00.62 \%)$ & $14(01.57 \%)$ \\
\hline 32 & $20(02.05 \%)$ & $6(00.68 \%)$ \\
\hline 33 & $12(01.24 \%)$ & $38(04.25 \%)$ \\
\hline 41 & $4(00.41 \%)$ & $21(02.35 \%)$ \\
\hline 42 & $40(04.11 \%)$ & $4(00.45 \%)$ \\
\hline 43 & $20(02.06 \%)$ & \\
\hline
\end{tabular}

Maxillary right central exhibited the highest prevalence of caries $33.44 \%$ and $33.82 \%$ in 2014 and 2015 respectively.

Table 8:- Prevalence of caries based on the surface of the tooth involved

\begin{tabular}{|c|c|c|}
\hline \multirow{2}{*}{ TOOTH SURFACES } & \multicolumn{2}{|c|}{ SURFACES WITH CARIES } \\
\cline { 2 - 3 } & $\mathbf{2 0 1 4}$ & $\mathbf{2 0 1 5}$ \\
\hline MESIAL & $\mathbf{7 3 0 ( 6 7 . 9 7 \% )}$ & $\mathbf{6 8 8}(\mathbf{6 6 . 4 7 \%})$ \\
\hline DISTAL & $285(26.54 \%)$ & $13(1.25 \%)$ \\
\hline LABIAL & $15(1.40 \%)$ & $19(1.83 \%)$ \\
\hline LINGUAL & $25(2.33 \%)$ & $14(1.35 \%)$ \\
\hline INCISAL & $19(1.77 \%)$ & $1.01 \%)$ \\
\hline
\end{tabular}


Prevalence of caries was most observed in the proximal surfaces, mesial $730(67.97 \%), 688(66.47 \%)$ and distal 285 (26.54\%), $321(31.01 \%)$ in 2014 and 2015 respectively.

\section{Discussion:-}

This study concluded that the distribution of caries was slightly higher in males than females, but not of much significance in contrast with the research conducted by Hegde $\mathrm{M} \mathrm{N}$ et al ${ }^{3}$ and the research conducted by Lukacs $\mathrm{J} \mathrm{R}$ et $\mathrm{al}^{4}$. The earlier studies attributed the higher prevalence of caries in anterior teeth in females to early eruption of teeth, longer exposure to cariogenic environment, easier access to food supplies and frequent snacking during food preparation. ${ }^{2}$ The decrease in the prevalence of caries among the female population may be due to an increase in the awareness of oral health importance among the rural population. Exposure to various oral health awareness programmes conducted in schools, colleges and in rural satellite dental care centres may also be a contributory factor to the decreased prevalence.

The prevalence of caries in anterior teeth was assessed in various age groups. Out of the 4000 patients examined, prevalence of caries was more in the age group of $36-55$ years of age. Similar results were recorded in studies conducted by Hegde $\mathrm{M} \mathrm{N}$ et al ${ }^{3}$ and Cleaton-Jones et al ${ }^{5}$.

The prevalence of caries in anterior teeth in the rural population was higher than that of the urban population in the year 2014 whereas in the year 2015 similar prevalence was observed. The higher prevalence of anterior caries in the earlier years corroborated by study conducted by Hegde M N et al may be due to various socio-economic factors, such as lack of knowledge and practice of oral hygiene practices, inadequate infrastructure and facilities available for oral health screening and treatment. ${ }^{6}$ The decrease in the disparity in prevalence of caries in the anterior teeth among the rural and urban population is due to the increase in oral health awareness among the rural population contributed by various oral health awareness programmes conducted by rural satellite centres located in the areas.

A strong correlation was observed between prevalence of caries in anterior teeth, diet excluding fish and diet including fish. Fish is a common part of the diet in population of Dakshina Kannada located in west coast of Karnataka, India. The decreased prevalence of caries in anterior teeth may be attributed to the increased intake of fish which is rich in fluoride and proteins. Proteins in the diet increase the $\mathrm{pH}$ in the oral environment due to putrefaction. Hence the population may be protected from dental caries. ${ }^{7,8,9}$

This study showed that the prevalence of caries was dependent on the oral hygiene habits of the population. It was observed that lesser the frequency of brushing higher the prevalence of caries in anterior teeth. Similar results were reported in studies conducted by Hegde M. N. et $\mathrm{al}^{3}$ and Tarsitani et $\mathrm{al}^{6}$.

Prevalence of caries was more in the maxillary anterior teeth than the mandibular anterior teeth. This finding may probably be due to the proximity of the mandibular teeth to the submandibular and sublinglual salivary gland duct openings. Similar findings were reported by Hegde M. N. et al and Mustafa D. et al.The results of the present study show that the prevalence of caries was most common in maxillary right central incisor followed by the maxillary left central incisor and maxillary right lateral incisor.

Certain areas of the tooth are more susceptible to caries such as pit and fissures and proximal surfaces. Approximal surfaces of the anterior teeth showed the highest prevalence of caries in accordance with the study conducted by Hegde M. N. et al and Mustafa De merci et al. ${ }^{10}$ Prevalence of caries was observed more in the mesial surface followed by the distal surface. This may be due to inadequate oral hygiene practices. Proximal surfaces of the anterior teeth are not self-cleansing hence may present as a retention area, thereby promoting caries

\section{Conclusion:-}

According to the study conducted it can be concluded that prevalence of caries in the anterior teeth can be strongly correlated with age, location, diet, oral hygiene habits and the surface of the tooth. Association between and gender and caries was not observed. 


\section{References:-}

1. Fejerskov Ole, Kidd Edwina, NyvadBente, BaelumVibeke editor. Dental Caries: the Disease and its Clinical Management.2nd ed.. Oxford: Blackwell Munksgaard; 2008

2. Featherstone JD. 2004. The continuum of dental caries: evidence for a dynamic disease process. J Dent Res 83:C39-C42.

3. Hedge MN, Hegde P, Bhat R, Rao LN, Dahiya R. Prevalence of dental caries in anterior teeth in South Canara population - a three year epidemiological study. Indian Journal of Applied Research. Vol:IV, Issue II, Feb-2014

4. Lukacs JR, Largaespada LL. Explaining sex differences in dental caries prevalence; saliva, hormones, and "lifehistory" etiologies. Am J Hum Bio. 2006 Jul-Aug;18(4):540-55

5. Cleaton-Jones Peter, Fattipaul. Dental caries trends in Africa. Community Dent Oral Epidemio. 199;27:316-320

6. Petti ,PanfiliPierluigi, SimonettiD'Arca Adele. Oral hygiene, sucrose consumption and dental caries prevalence in adolescent systemic fluoride non-users. Community Dent Oral Epidemiol. 1997;25:334-336

7. Tinanoff N, Palmer CA. Dietary determinants of dental caries and dietary recommendations for preschool children. J Public Health Dent. 2000;60:197-206|

8. Bardow A, Moe D, Nyvad B, Nauntofte B. The buffer capacity and buffer systems of human whole saliva measured without loss of CO2. Arch Oral Biol. 2000;45:1-12

9. Mithra N. Hegde, Amit Malhotra, Nidarsh D. Hegde.Prevalence of caries in anterior teeth in adults of Dakshina Kannada Indian population - An epidemiological study

10. Mustafa D, Safa T, Ahmet AY. Prevalence of caries on individual tooth surfaces and its distribution by age and gender in university clinic patients. Eur J Dent.2010;4(3):270-279. 